\title{
Changes in plant community diversity and aboveground biomass along with altitude within an alpine meadow on the Three-River source region
}

\author{
SA WenJun ${ }^{1 *}$, AN LiZhe $^{1} \&$ SA Wei ${ }^{2}$ \\ ${ }^{1}$ Institute of Botany Science, School of Life Sciences, Lanzhou University, Lanzhou 730000, China; \\ ${ }^{2}$ School of Life Science, Qinghai University, Xining 810008, China
}

Received April 23, 2012; accepted May 11, 2012; published online August 3, 2012

\begin{abstract}
The grassland is an important component of terrestrial ecosystems and plays a significant role in biodiversity and ecosystem functions. In the present study, the changes of plant species diversity and aboveground biomass productivity were examined along with the altitude in natural alpine grassland in the source region of three rivers on the Qinghai-Tibetan Plateau. Eleven experimental locations were selected with altitudes ranging from 3862 to $4450 \mathrm{~m}$ above sea level (a.s.l.). The results indicated that Kobresia pygmaea meadow, Kobresia humilis meadow and Salix cupularis shrub meadow had higher indices of diversity and aboveground biomass. The distribution of species diversity, richness and aboveground biomass showed similarly unimodal patterns across the altitude gradient with the highest indices appeared at mid-altitudes locations. The changing trend of species diversity, richness and evenness also showed significant unimodal patterns with total aboveground biomass, and the highest species diversity occurred at intermediate level of productivities. This research would provide a valuable reference for the protection of grassland biodiversity and maintaining of the grazing ecosystem function in the source region of the Three Rivers.
\end{abstract}

alpine meadow, species diversity, richness, evenness, aboveground biomass, Qinghai-Tibetan Plateau

Citation: Sa W J, An L Z, Sa W. Changes in plant community diversity and aboveground biomass along with altitude within an alpine meadow on the Three-River source region. Chin Sci Bull, 2012, 57: 3573-3577, doi: 10.1007/s11434-012-5287-8

Biological diversity plays an important role in the functioning and sustainability of the ecosystems [1]. The changes of plant community structure and decreasing productivity in grasslands in some areas were attributed to the overgrazing, mismanagement of natural grasslands and the destruction of biodiversity [2,3]. The productivity of ecosystem is regard as a good indicator to evaluate the impact of plant species diversity on function of ecosystem. Many efforts have been made to identify the relationship between species diversity and productivity. However, the observed effects of plant diversity on productivity have been inconsistent possibly due to the complexity in ecological characteristics among investigations [2-4]. In natural biological communities, the relationships between species diversity and productivity have been altering along with time and spatial scales $[3,4]$.

*Corresponding author (email: sawenjun@163.com)
Therefore, further work on relationship between species diversity and productivity at different scales and various ecological contents are still needed.

Qinghai Province is one of the main animal husbandry bases of China. It has natural pastureland of approximately 36.45 million hectares, of which there is alpine meadow of 24.00 million hectares, accounting for $65.06 \%$ of total pastureland in Qinghai [2]. The source region of the three major rivers (the Yangtze, Yellow and Lantsang rivers) is one of the most important areas for livestock grazing in Qinghai [5]. However, lack of scientific management of the pasture resources over a long time has led to overgrazing and rodent pest damage [6,7]. In addition, the human activity and global climate change jointly accelerate the potential for degradation of the alpine meadow in this region, and major changes to the species diversity of vegetation communities [5-7]. If a large amount of pastureland keeps degrading, not only the sustain- 
able development and local environmental quality will be threatened, but also the economic development in the lower reaches will be challenged [8]. Maintenance of diversity plays an essential role in the control of water and soil erosion, and keeping ecological balances in both the source area and the lower reaches of the three rivers [2-4,6,7].

The relationship between biological diversity and their productivities in the natural communities could be reflection of species diversity during long-term of evolution $[3,4]$. However, only few works have been conducted on the relationship between the species diversity and productivity of alpine meadow, especially in the high mountain area [2-8]. This study was carried out in different types of natural vegetation communities in the alpine meadow zone, across a range of altitudes. The trends of the aboveground biomass along with altitude and the relationship between community diversity and aboveground biomass were analyzed. This research would provide a basic reference for the protection and sustainable use of the natural grassland resources, and the rehabilitation of degraded grassland by using natural vegetation [9] in the Three Rivers District.

\section{Materials and methods}

\subsection{Study area and sample collection}

The study was carried out at Jianshe township, Dari County, Guoluo Prefecture, in the hinterland of the Three Rivers District, Qinghai Province $\left(33^{\circ} 40^{\prime}-33^{\circ} 42^{\prime} \mathrm{N}, 9^{\circ} 23^{\prime}-\right.$ $\left.99^{\circ} 26^{\prime} \mathrm{E}\right)$. This area is relatively less affected by grazing activity as animal graze on these grasslands only in winter and spring. The sampling sites were located in a wide valley stretching from southwest to northeast with an average altitude of $4156 \mathrm{~m}$ a.s.l. This region has a typical plateau continental climate with an annual mean precipitation of 571.2 $\mathrm{mm}$ and annual mean air temperature of $0.3^{\circ} \mathrm{C}$. The annual accumulated air temperature above $0^{\circ} \mathrm{C}$ is $824.6^{\circ} \mathrm{C}$ and growth duration is $124 \mathrm{~d}$. The main vegetation types are alpine meadow and alpine shrub meadow. The dominant species are Kobresia pygmaea, Kobresia humilis, Kobresia tibetica, Kobresia capillifolia, Poa pratensis, Carex tristachya, Salix cupulari. The main soil types are alpine meadow soil and alpine shrub meadow soil.

In August 2010, eleven experimental sites $(50 \mathrm{~m} \times 50 \mathrm{~m})$ were chosen at the altitude gradients ranging from 3862 to $4450 \mathrm{~m}$ along the valley. Five sampling quadrats $(1 \mathrm{~m} \times 1 \mathrm{~m}$ and $5 \mathrm{~m} \times 5 \mathrm{~m}$ for shrub meadow) were selected from each area of $50 \mathrm{~m} \times 50 \mathrm{~m}$. The detailed geographical information of the samples and the numbers of plant species, the average vegetation height and the vegetation coverage for each sampling sites are listed in Table 1.

\subsection{Determination of plant aboveground biomass}

The aboveground plant material was cut and dissected to determine the fresh weight of monocotyledons, dicotyledons and shrubs in each sample. The samples were dried at $80^{\circ} \mathrm{C}$ in the thermostated container until a constant weight. The aboveground biomass was separated into monocotyledons (Gramineae and Cyperus etc.), dicotyledons (Leguminosae and Compositae etc.) and shrubs.

\subsection{Processing of data}

Relative vegetation cover was used to calculate indices of the richness, evenness and species diversity using the following methods $[10,11]$ :

Richness index: $R=S$,

Shannon-Wiener index: $H^{\prime}=-\Sigma P_{\mathrm{i}} \ln P_{\mathrm{i}}$,

Pielou evenness index: $J=H^{\prime} / \ln S$,

where $P_{\mathrm{i}}$ is the relative cover of species i; $S$ is the total number of species $i$ in a certain sample.

Origin Pro 8.0 software package was used for graphing and data analysis.

\section{Results and discussion}

\subsection{Characteristics of the vegetation community}

The dominant plant species were used to represent each of the vegetation communities. There were nine vegetation community types recorded across the 11 sampling sites along the elevation gradients (Table 1). The main types were composed of $K$. pygmaea meadow, $K$. humilis meadow, K. pygmaea+Carex tristachya meadow, $K$. pygmaea $+K$. capillifolia meadow, $K$. pygmaea $K$. tibetica, K. pygmaea + Poa pratensis meadow, $K$. pygmaea $+P$. anserina meadow, $S$. cupularis + Carex tristachya shrub meadow, $S$. cupularis $+K$. capillifolia shrub meadow.

In such natural environments, the species compositions of different vegetation communities are the result of adaptation to local conditions. In the long-term evolution, the different vegetation communities developed specific structures and species compositions [2]. In this study, the species diversity in the $K$. pygmaea+C. tristachya meadow was the highest, and the lowest diversity in the $K$. pygmaea meadow at the highest altitude sites.

The evenness index decreased in the order of $K$. pygmaea meadow, $K$. humilis meadow, $S$. cupularis shrub meadow and $K$. pygmaea $+P$. anserina meadow. The evenness index in the $K$. pygmaea community and $K$. humilis community was relatively higher because their dominant species were more evenly distributed. In contrast, there were only 1 or 2 dominant species in the $K$. pygmaea $P$. anserina meadow, which might account for the relatively lower evenness index. The highest total aboveground biomass was observed in $S$. cupularis shrub meadow while the lowest aboveground biomass was found in $K$. pygmaea meadow at the highest altitude sites due to the relatively simple community structure compared with the others (Table 1). 
Table 1 Geographical information, vegetation coverage, average height, species diversity indices and aboveground biomass at 11 elevation sites

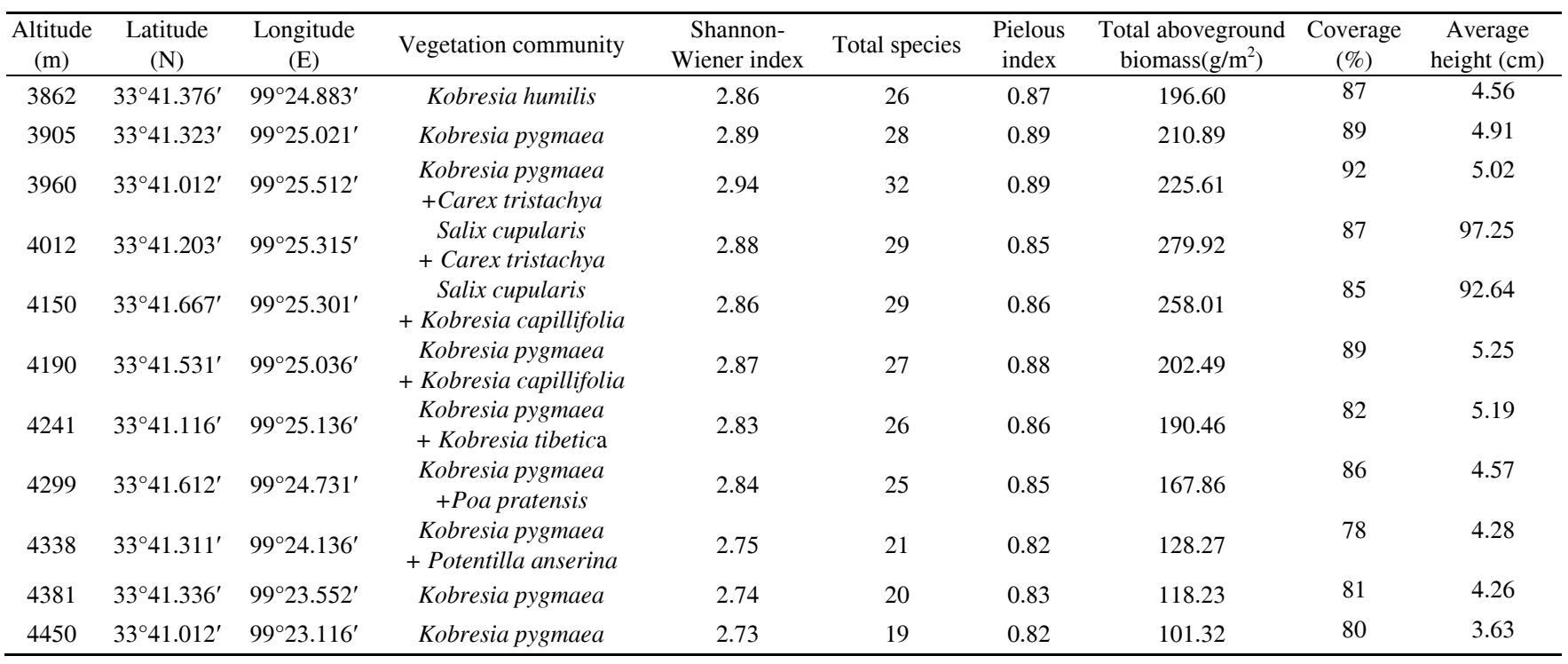

\subsection{Relationship of community diversity with altitude}

The indices of Shannon-Wiener, richness and evenness of the species diversity varied greatly with altitude (Table 1). The Shannon-Wiener index of the species diversity increased with altitude from 3862 to $3960 \mathrm{~m}$, and reached the maximum at the elevation of $3960 \mathrm{~m}$. Above that point, the Shannon-Wiener index generally decreased with the increasing of elevations, and the lowest index of ShannonWiener was found at the highest altitude of $4450 \mathrm{~m}$ (Figure 1(a)). The distribution of the species richness and evenness along the altitude were similar to the variations of species diversity index (Figure 1(b) and (c)). The maximum species richness index also occurred at the elevation of $3960 \mathrm{~m}$, and the lowest index of species richness occurred at the elevation of $4450 \mathrm{~m}$. The evenness of the species varied between 0.82 (at altitudes of 4338 and $4450 \mathrm{~m}$ ) and 0.89 (at altitudes of 3905 and $3960 \mathrm{~m}$ ).

The trends of species diversity, richness and evenness with altitude were well described by negative quadratic functions with correlation coefficients $R$ of $0.9294,0.9402$ and 0.8466, respectively $(P<0.05)$ (Figure 1(a)-(c)), which suggested that their distribution clearly showed unimodal patterns across the eleven altitude gradients. In such extreme environmental conditions, especially at highest altitude with lowest temperature stress, some vegetation species disappeared and the species diversity accordingly became lower. The greatest species diversity was found at middle level altitudes whereas multi-dominant species communities led to higher richness and evenness. This observation was similar to the results by Wang et al. [4] and Gentry [12] who also described a "mid-domain" distribution pattern of plant species diversity with the elevations.

\subsection{Relationship of aboveground biomass with altitude}

The aboveground biomass increased with altitude from $3862 \mathrm{~m}$ and reached maximum at elevation of $4012 \mathrm{~m}$ and then decreased with increasing elevation (Table 1). The changing trend of aboveground biomass with altitude showed a negative quadratic function with the coefficient $\mathrm{R}$ of 0.9251 (Figure 2(a)). In the present study area, the monocotyledonous biomass was found to contribute $49.58 \%-$ $68.55 \%$ (average $60.22 \%$ ) to the total aboveground biomass, suggesting the monocotyledons biomass had a major
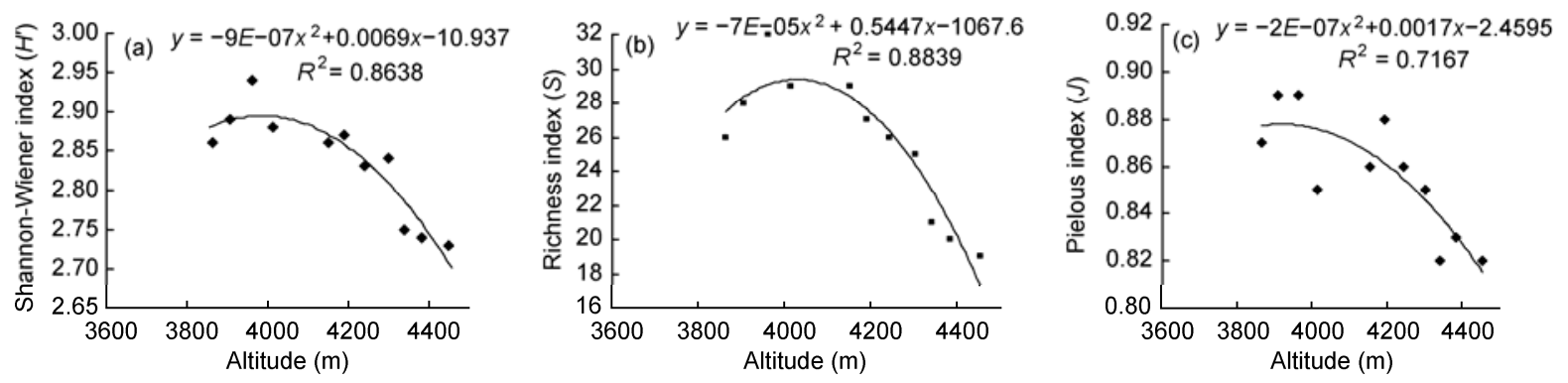

Figure 1 Relationship of species diversity, richness and evenness index with altitude. (a) Species diversity; (b) richness index; (c) evenness index. 

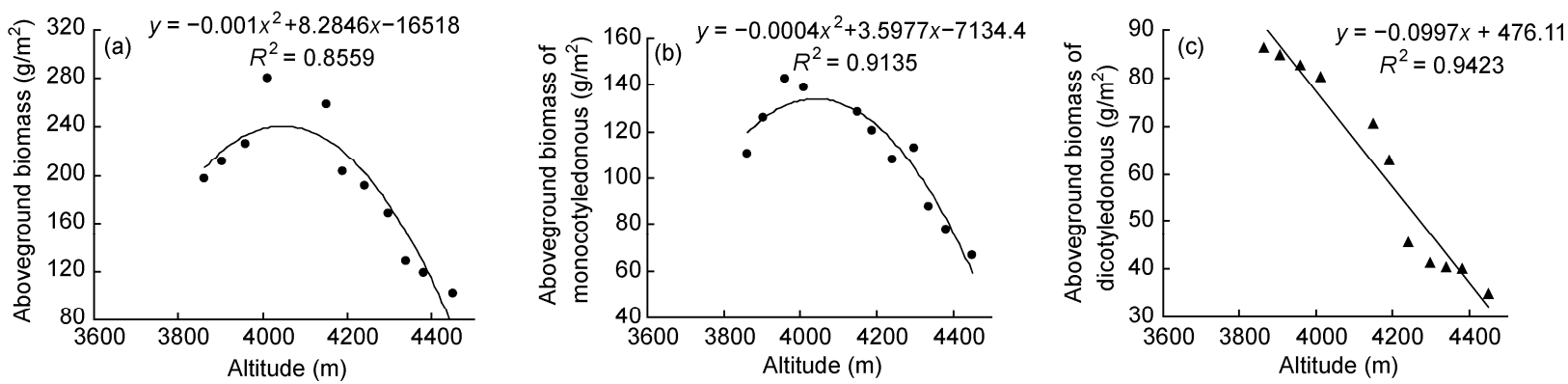

Figure 2 Relationship of aboveground biomass with altitude. (a) Total biomass; (b) monocotyledonous biomass; (c) dicotyledonous biomass.

influence to the overall vegetation community. The distribution of monocotyledons aboveground biomass with altitude was consistent with that of the total aboveground biomass (Figure 2(b)). The dicotyledonous biomass was found to contribute $23.92 \%-43.90 \%$ (average $32.40 \%$ ) to the total aboveground biomass. The changing trend of dicotyledonous biomass with altitudes exhibited a different distribution pattern. The dicotyledonous biomass decreased with the increasing of the altitude showing a significantly negative linear correlation $(P<0.05)$ (Figure 2(c)).

\subsection{Relationship of species diversity with aboveground biomass}

The changes in plant diversity at different locations depend on interspecies competition for the limited resources of the plant community [13]. Plant species richness can affect the stability of the grassland ecosystem [14]. The species diversity, richness and evenness were greatest at an intermediate level of aboveground biomass $\left(225.61 \mathrm{~g} / \mathrm{m}^{2}\right)$. The lowest Shannon-Wiener index occurred at the highest altitude sites with the lowest biomass production $\left(101.32 \mathrm{~g} / \mathrm{m}^{2}\right)$.

The relationships of the species diversity, richness and evenness with the total aboveground biomass showed unimodal distribution patterns, which can be described by quadratic functions with correlation coefficients $R$ of 0.9333 , 0.9533 and 0.8953 , respectively (Figure 3(a)-(c)). This result was consistent with the findings by Kassen et al. [15], Yang et al. [16] and Wang et al. [3] who observed that the higher species diversity, richness and evenness occurred in the middle level of productivities. On the one hand, the nutrient availability was usually higher at the lower altitude, which made a few species so robust and thus the less competitive species were excluded [4]. On the other hand, the richness and evenness of the species usually were lower due to the restrictions by the hash environmental conditions at the highest altitude areas, which accounted for the relatively lower diversity and lower biomass productivity.

\subsection{Implications for utilization and protection on the grassland ecosystem}

Species diversity can be influenced by many factors including environmental and human factors [17]. It is difficult to change the environmental factors, but we can protect the species diversity by effectively controlling human activities, particularly in relation to livestock management, according to different environmental conditions.

To protect grassland biodiversity and maintain the grazing ecosystem function in the source region of the Three Rivers in Qinghai-Tibetan Plateau, we can carry out different grassland and livestock management measures according to the specific environmental condition [18-21]. For example, we can graze different types of animals in different types of grassland. The K. pygmaea meadow is suitable for grazing by yak and Tibetan sheep, whereas the Kobresia swamp meadow is suitable for grazing yak only [19]. Because vegetation species diversity and aboveground biomass generally drops with the increasing of altitude, we should adjust grazing intensity according to the altitude of the
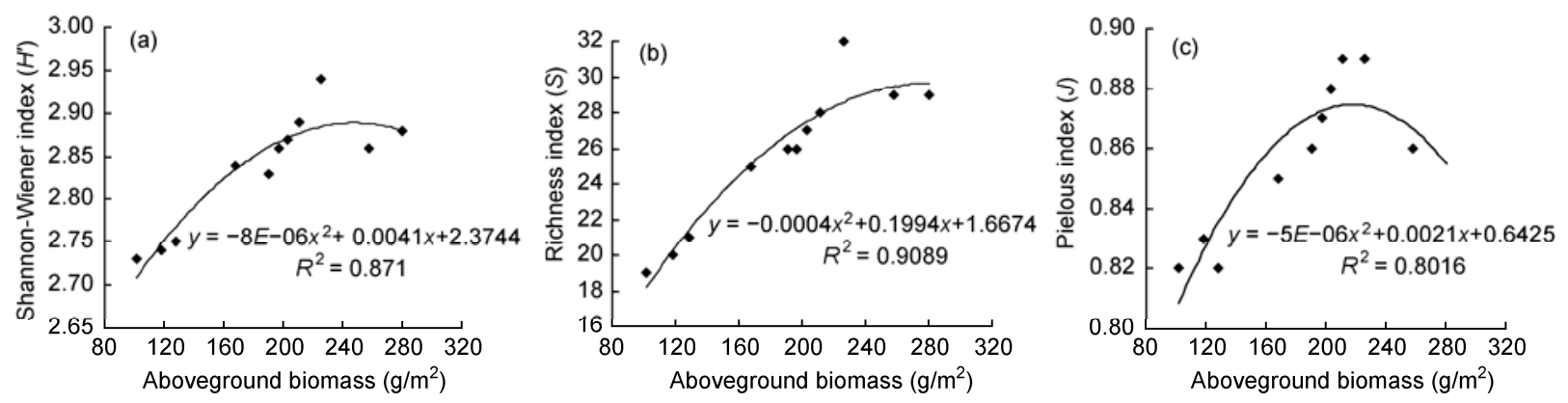

Figure 3 Relationship of Shannon-Wiener index, richness index and evenness index with aboveground biomass. (a) Shannon-wiener index; (b) richness index; (c) evenness index. 
specific grassland in order to protect the species diversity and grassland [21].

\section{Conclusions}

This study examined the species diversity for different vegetation communities across a range of altitudes in natural alpine grassland in the headwater region of the Three Rivers. The $K$. pygmaea meadow is the main type of grassland in the study area and also it has the highest indices of species diversity, richness and evenness. The trends of the species diversity, aboveground total biomass and monocotyledonous biomass showed similar unimodal distribution patterns along with the elevation gradient that the highest species diversity and productivity occurred at the mid-altitude area (3960-4150 m). In contrast, the aboveground dicotyledonous biomass exhibited the trend of continuous decline with the increasing of altitude. The changes in species diversity and productivity of the different vegetation communities could be influenced by the characteristics of individual species and environmental conditions. Further research is still necessary to get a better understanding of the effects of environmental factors such as temperature, soil nutrient and human disturbance (including grazing intensity) on community diversity in this region.

1 Tilman D, Wedin D, Knops J. Productivity and sustainability influenced by biodiversity in grassland ecosystem. Nature, 1996, 379: 718-720

2 Wang C T, Long R J, Wang Q L, et al. Changes in plant diversity, biomass and soil $\mathrm{c}$, in alpine meadows at different degradation stages in the headwater region of three rivers, China (in Chinese). Land Degrad Develop, 2009, 20: 187-198

3 Wang C T, Long R J, Wang Q J, et al. Relationship between species diversity and productivity in four types of alpine meadow plant communities (in Chinese). Chin J Ecol, 2005, 24: 483-487

4 Wang C T, Wang Q J, Long R J, et al. Changes in plant species diversity and productivity along an elevation gradient in an alpine meadow (in Chinese). Chin J Plant Ecol, 2004, 28: 240-245

5 Liu W, Zhou H, Zhou L. Biomass distribution pattern of degraded grassland in alpine meadow (in Chinese). Chin J Grassland, 2005, 27 : 9-15

6 Cui Q H, Jiang Z G, Liu J K, et al. A review of the cause of rangeland degradation on Qinghai-Tibetan Plateau. Chin J Grassland, 2007, 24: 20-26

7 Wang W Y, Wang Q J. The structure and plant species diversity of the degraded ecosystems in alpine Kobresia meadow (in Chinese). Acta Pratacul Sci, 2001, 10: 8-14

8 Wu G L, Du G Z. Discussion on ecological construction and sustainable development of degraded alpine grassland ecosystem of the Qinghai-tibetan plateau (in Chinese). Chin J Nat Sci, 2007, 29: 159-164

9 Du G Z, Qin G L, Li Z Z, et al. Relationship between species richness and productivity in an alpine meadow plant community (in Chinese). Chin J Plant Ecol, 2003, 27: 125-132

10 Ma K P, Huang J H, Yu S L. Study in species diversity, richness index, evenness index, species diversity index of vegetation community in donglingshan Area in Beijing (in Chinese). Ecol J, 1995, 15: 268-277

11 Ma K P, Liu Y M. Measure method of biocommunity's diversity (in Chinese). Chin Biodiv, 1994, 2: 231-239

12 Gentry A H. Changes in plant community diversity and floristic composition on environmental and geographical gradient. Annu Missouri Bot Garden, 1988, 75: 1-34

13 Li Y H. Grazing dynamics of the species diversity in aneurolepodium chinense steppe and stipa grandis steppe (in Chinese). J Integr Plant Biol, 1993, 35: 877-884

14 Zhao P, Peng S L, Zhang J W. Restoration ecology-An effective way to restore biodiversity of degraded ecosystems (in Chinese). Chin J Ecol, 2000, 19: 53-58

15 Kassen R, Angus B, Graham B. Diversity peaks at intermediate productivity in a laboratory microcosm. Nature, 2000, 406: 508-511

16 Yang L M, Zhou G S, Li J D. Relationship between species diversity and productivity in sunnun plain of grassland plant communities (in Chinese). Chin J Ecol, 2005, 24: 483-487

17 Zhang D Y. Research of Theoretical Ecology (in Chinese). Beijing: Higher Education Press, 2000. 151-200

18 Ren Q J, Wu G L, Ren G H. Effect of grazing intensity on characteristics of alpine meadow communities in the eastern Qinghai-Tibetan Plateau (in Chinese). Chin J Grassland, 2009, 18: 256-261

19 Dong Q M, Ma Y S, Li Q Y. Effect of grazing intensity on the growth of yak (in Chinese). Chin J Grassland, 2003, 11: 256-260

20 Li H T, Zhen W, Dong Q M, et al. Effect of different grazing intensity on above-ground net primary productivity and re-growth biomass in alpine-cold grassland around qinghai lake. Chin Qighai J Animal Veterinary Sci, 2011, 4: 13-15

21 Wang M J, Han G D, Cui G W, et al. Effect of grazing intensity on the biodiversity and productivity of alpine meadow (in Chinese). Chin J Ecol, 2010, 29: 862-868

Open Access This article is distributed under the terms of the Creative Commons Attribution License which permits any use, distribution, and reproduction in any medium, provided the original author(s) and source are credited. 